\title{
Coupling of the Adhesive Receptor CD11b/CD18 to Functional Enhancement of Effector Macrophage Tissue Factor Response
}

Sao-Tah Fan and Thomas S. Edgington

Department of Immunology, Research Institute of Scripps Clinic, La Jolla, California 92037

\begin{abstract}
Initiation and regulation of localized selective proteolysis is an important effector property of cells of macrophage (Mo) lineage. Among such effector responses is the induced expression of tissue factor (TF) by cells of Mo lineage. In characterizing the regulation of the Mo responses that may influence the magnitude of the effector phase of the cellular immune response, we have identified a role for the cell surface adhesive receptor CD11b/CD18 (Mac-1, CR3) to amplify the induced TF response. Occupancy of CD11b/CD18 by MAb as surrogate ligands does not directly initiate a TF response. In contrast, after either $T$ cell-derived cytokine or LPS as initial signals, engagement of CD11b/CD18 by MAb induces a two- to eight-fold functional enhancement of the TF response in murine and human Mo. This pathway of CD11b/CD18 enhancement of this Mo effector response was also confirmed with recognized ligands for CD11b/CD18 by exposure of Mo to immobilized fibrinogen. A quantitative increase of Mo surface expression of TF was validated by flow cytometry. We suggest that engagement of CD11b/CD18 by complementary ligands including adherence to extracellular matrix, and possibly in antigen-driven $\mathbf{T}_{\mathbf{H}}$ :Mo collaborative responses, results in the transduction of cellular signals that quantitatively enhance the expression of TF per se and thereby enhance the inflammatory component of Mo mediated response. (J. Clin. Invest. 1991. 87:50-57.) Key words: integrin • tissue factor $\bullet$ adhesive receptor $\bullet$ macrophage
\end{abstract}

\section{Introduction}

The procoagulant response (PCA) ${ }^{1}$ of monocytes and macrophages (Mo) can be elicited by antigen-driven $T_{H}$ or by bacterial LPS. The PCA effector molecule is commonly tissue factor (TF). TF is a transmembrane glycoprotein and high affinity receptor for factor VII and VIIa, and cofactor for factor VIIa

Address correspondence and reprint requests to Dr. Thomas S. Edgington, Department of Immunology (IMM-17), Research Institute of Scripps Clinic, 10666 North Torrey Pines Road, La Jolla, CA 92037.

Received for publication 20 November 1989 and in revised form 8 August 1990.

1. Abbreviations used in this paper: CRPMI, complete culture medium; MLC, mixed lymphocyte culture; Mo, monocyte/macrophage; MPIF, monocyte procoagulant inducing factor; PCA, procoagulant activity; PEC, murine peritoneal exudate cells; $\mathrm{SN}$, tissue culture supernatant medium; TF, tissue factor.

J. Clin. Invest.

(c) The American Society for Clinical Investigation, Inc.

0021-9738/91/01/0050/08 \$2.00

Volume 87, January 1991, 50-57 initiation of the coagulation protease cascades $(1,2)$. The TF gene is silent in unstimulated Mo, requiring de novo initiation of transcription as an initial step in biosynthesis (3). Induction of the cellular PCA response has been associated with injury in virus-induced and apparently immune-mediated pathogenetic responses (4-6), and the in vitro response has been used as a measure of cellular immune responses to antigen $(7,8)$.

Analysis of the mechanisms of induction of the Mo PCA/ TF response by cloned antigen-specific $T_{H}$ has identified two categorical classes of cellular collaboration between activated $T_{H}$ and Mo for both man (9) and mouse (10). Whereas one pathway is mediated by the $T_{H^{-}}$-derived cytokine(s) designated monocyte procoagulant inducing factor (MPIF) (11-13), a second pathway uses apparent contact collaboration between $T_{H}$ and Mo $(9,10)$. The structure of MPIF and the surface molecules on the T cells and Mo involved in the collaborative induction of the PCA response remain to be established, though apparently independent of established cytokines $(11,12)$ and do not involve an MHC restriction of the effector collaboration between $T_{H}$ and Mo (10). Preliminary evidence suggested that perhaps CD11b/CD18 (Mac-1, CR3) might be implicated in this cell:cell collaboration (14).

$\mathrm{CD} 11 \mathrm{~b} / \mathrm{CD} 18$ is one of the three major leukocyte integrins, a family of heterodimeric adhesive receptors (15). $\mathrm{CD} 1 \mathrm{lb} / \mathrm{CD} 18$ functions in an oligospecific manner as a receptor for C3bi (16), factor X (17), fibrinogen $(18,19)$, and possibly for LPS (20). Biological roles of CD11b/CD18 have been established in: $(a)$ attachment and phagocytosis of particles coated with C3bi by granulocytes and macrophages (21); (b) phagocytosis of opsonized pathogens such as Leishmania (22, $23)$; (c) the rapid initiation of a novel coagulation protease cascade (24); as well as $(d)$ mechanisms of cell migration $(25,26)$. In recent studies, ligation of CD11b/CD18 on mouse peritoneal Mo elicited effects associated with Mo activation (27). In addition, ligation of members of the CD11/CD18 leukocyte integrin family may be required for the maximum respiratory burst response of PMN to cytokines (28); and ligation of $\mathrm{CD} 11 \mathrm{~b} / \mathrm{CD} 18$ was subsequently implicated as the receptor responsible for the adhesion-dependent respiratory burst by human and canine PMN exposed to chemotactic factors (29). Similarly, ligation of CD1 1a/CD18 (LFA-1) has been observed to augment IL-2 production and proliferation by $\mathrm{T}$ cells after engagement and crosslinking of CD3 molecules (30). We now present evidence that engagement of CD11b/CD18 leads to enhancement of a relevant effect in Mo, namely, it results in a marked enhancement of the TF-mediated PCA activity of Mo in response to both T cell-derived cytokines and LPS. Our results together with others (28-30), suggested that engagement of CD1 1/CD18 molecules can transmit a co-stimulatory signal in a variety of cells for expressing various effector functions. We suggest that such augmentation may play an important role in the structure and functional behavior of inflammatory lesions in tissues. 


\section{Methods}

Animals. 2- to 3-mo-old C3H/HeN, C57BL/6, and BALB/c mice were obtained from the breeding colony of the institute and fed ad lib.

Cell preparations. Human PBMC were isolated from heparinized blood of volunteer donors on Ficoll-Hypaque gradients (9). Human Mo were isolated from PBMC by brief adherence to autologous serum coated culture dishes (19). Mouse peritoneal exudate cells (PEC) were harvested by irrigation 2-3 d after intraperitoneal injection of $3 \mathrm{ml}$ of selected low LPS thioglycollate medium (Difco Laboratories Inc., Detroit, MI) as previously described (10).

Culture medium, reagents, and MAbs. Selected very low endotoxin ( $<10 \mathrm{pg} / \mathrm{ml}$ ) RPMI 1640 (M.A. Bioproducts, Walkersville, MD) supplemented with 10\% FCS (Irvine Scientific, Santa Ana, CA), $25 \mathrm{mM}$ Hepes, $5 \times 10^{-5} \mathrm{M} 2-\mathrm{ME}$, and $10 \mu \mathrm{g} / \mathrm{ml}$ gentamycin was used as complete culture medium (CRPMI) (10). LPS, Escherichia coli 0111:B4, was purchased from Behring Diagnostics (La Jolla, CA). Single coagulation factor-deficient human plasma were purchased from George King Biomedical Inc. (Overland Park, KS), and the factor VII-deficient plasma was further depleted with immobilized MAb to factor VII/VIIa. Human fibrinogen was purified from plasma (31) and was homogeneous as judged by SDS-PAGE. Rat hybridomas M1/70 (anti-CD1 1b) (32), M18/2 (anti-CD18) (33), GK1.5 (anti-CD4) (34), mouse hybridomas 26-8-16s (anti-I- $\left.A^{k}\right)(35)$, anti- $K^{b}$ monoclonal antibodies 5F1.2 and Y-3 (36), and mouse anti-CD1 lb hybridomas OKM1, OKM10, were obtained from American Tissue Culture Collection (Bethesda, MD). Anti-CD18 MAb 60.3 was a gift of Dr. P. G. Beatty (Oncogene Inc., Seattle, WA) and mouse anti-human TF MAb 5G9 was from our laboratory (37). Antibodies were prepared from culture supernatant or from ascites fluid by protein A coupled to Bio-Rad Affigel (Bio-Rad Laboratories, Richmond, CA; manufacturer's instructions). All materials, other than LPS, were very low endotoxin based on the PCA response and amoebocyte lysate assay.

Generation of lymphocyte culture tissue culture supernatant medium. For lymphokine-rich tissue culture supernatant medium (SN) from allogeneic stimulated cultures, one-way mixed lymphocyte culture (MLC) were performed as previously described (10). Briefly, for murine primary MLC $2 \times 10^{6}$ responder lymph node cells were mixed with equal numbers of irradiated (3,000 rad) stimulator spleen cells in 16-mm culture wells in $2 \mathrm{ml}$ of CRPMI. For secondary responses, viable cells harvested $14 \mathrm{~d}$ after primary stimulation were cultured at 1 $\times 10^{6}$ cells with $3 \times 10^{7}$ irradiated stimulator cells in $10 \mathrm{ml}$. Supernatant medium (MLC SN) of secondary MLC was harvested 24-48 h after restimulation. Human lymphokine-rich medium (PHA SN) containing MPIF activity was generated by incubating human PBMC at 1 $\times 10^{6} / \mathrm{ml} \mathrm{CRPMI} \mathrm{with} 10 \mu \mathrm{g} / \mathrm{ml}$ PHA at $37^{\circ} \mathrm{C}$ for $48 \mathrm{~h}$.

Fibrinogen and fibrin coated surfaces. To 96-well tissue culture flat bottom plates (No. 3596; Costar, Cambridge, MA), $100 \mu$ l of fibrinogen $(0.8 \mathrm{mg} / \mathrm{ml})$ or purified MAb $(0.3 \mathrm{mg} / \mathrm{ml})$ was added to each well, incubated for $1 \mathrm{~h}$ at $25^{\circ} \mathrm{C}$, and plates were washed three times with RPMI. For preparation of fibrin matrix, $50 \mu$ l of citrated plasma mixed with equal volume of $20 \mathrm{mM} \mathrm{CaCl}_{2}$ were added to each well and was immediately removed, leaving a thin coating. Plates were incubated for $10 \mathrm{~min}$ at $37^{\circ} \mathrm{C}$, and were washed three times with $20 \mathrm{mM} \mathrm{CaCl}_{2}$ to dissociate thrombin from fibrin.

Induction of PCA in Mo. Mouse PEC harvested 2-3 d after intraperitoneal injection of thioglycollate were washed and resuspended in RPMI at $2-5 \times 10^{6}$ cells $/ \mathrm{ml}$. Human PBMC or isolated Mo were resuspended in RPMI at $10^{7}$ and $10^{6} / \mathrm{ml}$, respectively. Aliquots of $100 \mu \mathrm{l}$ of cell suspension were added to each well of a 96-well microtiter plate followed by $50 \mu \mathrm{l}$ of experimental reagents in CRPMI. After $5 \mathrm{~h}$ (or as otherwise indicated) incubation at $37^{\circ} \mathrm{C}$, cells were pelleted, snap frozen and held at $-70^{\circ} \mathrm{C}$, and assayed for total cellular PCA.

Assay of total cellular PCA. Functional PCA was quantitated as previously described (38) based on acceleration of coagulation of recalcified human plasma with slight modification. Cell pellets from either $2-5 \times 10^{5} \mathrm{PEC} /$ well or $10^{6}$ human PBMC, were frozen, thawed, and resuspended in 80-150 $\mu \mathrm{l}$ of SN from PEC cultured for $24 \mathrm{~h}$ or $25 \mathrm{mM}$
Hepes-saline, respectively, with vigorous agitation by pipetting repeatedly and placed on ice. $50 \mu \mathrm{l}$ of each sample were mixed with an equal volume of $20 \mathrm{mM} \mathrm{CaCl}_{2}$ in borosilicate glass test tubes at $37^{\circ} \mathrm{C}$, and the assay was initiated with $50 \mu \mathrm{l}$ of standardized pooled citrated normal human platelet-poor plasma and clotting time was measured with systematic rocking. Rabbit brain thromboplastin standard curves were used as arbitrary reproducible standards in $\log -\log$ plots to convert the clotting time to milliunits of PCA (10).

FACS analysis for cell surface TF. Costar 24-well plates (No. 3424) were coated with OKM1 $(0.1 \mathrm{mg} / \mathrm{ml})$, fibrinogen $(0.3 \mathrm{mg} / \mathrm{ml})$, or control FCS $(10 \%$, vol/vol) for $1 \mathrm{~h}$ at room temp then washed three times. Human PBMC, incubated for $5 \mathrm{~h}$ under stated experimental conditions at $2 \times 10^{6} \mathrm{cell} / \mathrm{ml}$ and $1 \mathrm{ml} /$ well, were detached from the plates by gentle scraping with rubber policemen. After washing, cells were incubated with biotinylated anti-TF MAb $5 \mathrm{G} 9(50 \mu \mathrm{g} / \mathrm{ml})$ for $20 \mathrm{~min}$ at $0^{\circ} \mathrm{C}$, washed, and reacted with streptavidin-phycoerythrin conjugate (Tyco Inc., Burlingame, CA). Samples for specificity control were incubated with nonlabeled $5 \mathrm{G} 9$ at $0.3 \mathrm{mg} / \mathrm{ml}$ for $3 \mathrm{~min}$ before adding the biotinylated 5G9. The labeled Mo population was analyzed for bound MAb with a FACS IV flow cytometer (Becton Dickinson \& Co., Mountain View, CA) as previously described (24).

Chromogenic Xa generation assay for TF. PEC at $5 \times 10^{5} /$ well in 96-well plates were pelleted, freeze-thawed, and vigorously resuspended in $30 \mu \mathrm{l}$ Hepes-saline containing $10 \mathrm{mM} \mathrm{CaCl}{ }_{2}$ by repeated pipetting. To some wells containing cells previously washed with 10 mM EDTA, $10 \mu \mathrm{l}$ of $20 \mu \mathrm{g} / \mathrm{ml}$ purified human factor VII was added to give $100 \mathrm{nM}$ VII. After addition of $10 \mu \mathrm{l}$ of $2 \mu \mathrm{M}$ factor $\mathrm{X}$ to each well, the plate was incubated at $37^{\circ} \mathrm{C}$ for $1-5 \mathrm{~min}$. A total of $10 \mu \mathrm{l}$ of $500 \mathrm{mM}$ EDTA were added to wells at each time point to stop the reaction. Aggregates of cell fragments were pelleted and $50 \mu \mathrm{l}$ of SN were transferred to wells containing $10 \mu \mathrm{l}$ of $2 \mathrm{mM}$ Spectrozyme FXa (American Diagnostica Inc., New York) and the rate of substrate hydrolysis was determined within the first minute using a kinetic microplate reader (Molecular Devices, Menlo Park, CA).

Intracellular calcium quantitation. Cytosolic $\mathrm{Ca}^{2+}$ was assayed as previously described (39) following the protocols of Wade and McQuinston (Meridian Instruments Inc., Okemos, MI) using Indo-1 free acid and Indo-1/AM (Calbiochem-Behring Corp., La Jolla, CA) which had been dissolved in DMSO at $1 \mathrm{mM}$ and stored at $-70^{\circ} \mathrm{C} .200$ $\mu \mathrm{l}$ of PEC at $1 \times 10^{7}$ cells per $\mathrm{ml}$ Indo-1 loading medium $(145 \mathrm{mM}$ $\mathrm{NaCl}, 5 \mathrm{mM} \mathrm{KCl}, 1 \mathrm{mM} \mathrm{Na} \mathrm{HPO}_{4}, 2.5 \mathrm{mM} \mathrm{CaCl}_{2}, 0.5 \mathrm{mM} \mathrm{MgSO}_{4}$, $10 \mathrm{mM}$ glucose, $25 \mathrm{mM}$ Hepes, $\mathrm{pH} 7.2,1 \mu \mathrm{M}$ Indo-1/AM) were placed on a $22-\mathrm{mm}^{2}$ grade 1 glass coverslip $<0.16-\mathrm{mm}$ thickness and incubated at $37^{\circ} \mathrm{C}$ in $5 \% \mathrm{CO}_{2} /$ air for $1-2 \mathrm{~h}$. Attached cells were gently washed twice and covered with $300 \mu$ l of fresh Indo-1 loading buffer, protected in the dark at room temperature from photobleaching, and immediately analyzed. All the experiments were performed within $2 \mathrm{~h}$ from the Indo-1 loading procedure. Real-time transients in intracellular $\mathrm{Ca}^{2+}$ of attached PEC were recorded by an Anchored Cell Analysis and Sorting interactive laser cytometer (ACAS, model 470; Meridian Instruments) as described (39).

\section{Results}

Induction of murine macrophage PCA response. The postulated role of $\mathrm{CD} 1 \mathrm{lb} / \mathrm{CD} 18$ as a recognition structure for collaborative induction of the Mo PCA response (14) was first examined using soluble MAbs. Since initial studies demonstrated no effect in any of the modes of analysis described in this study, and only anti-CD11b/CD18 exhibited some effect, we used MAbs specific for this member (Mac-1, CR3) of the leukocyte integrin family, for the leukocyte integrins as a group, and for other Mo surface molecules. Each was used as a surrogate ligand to engage these molecules on murine PEC coupled with analysis of primary or synergistic induction of the PCA response. As shown in Fig. $1 A$, none of the MAbs to 

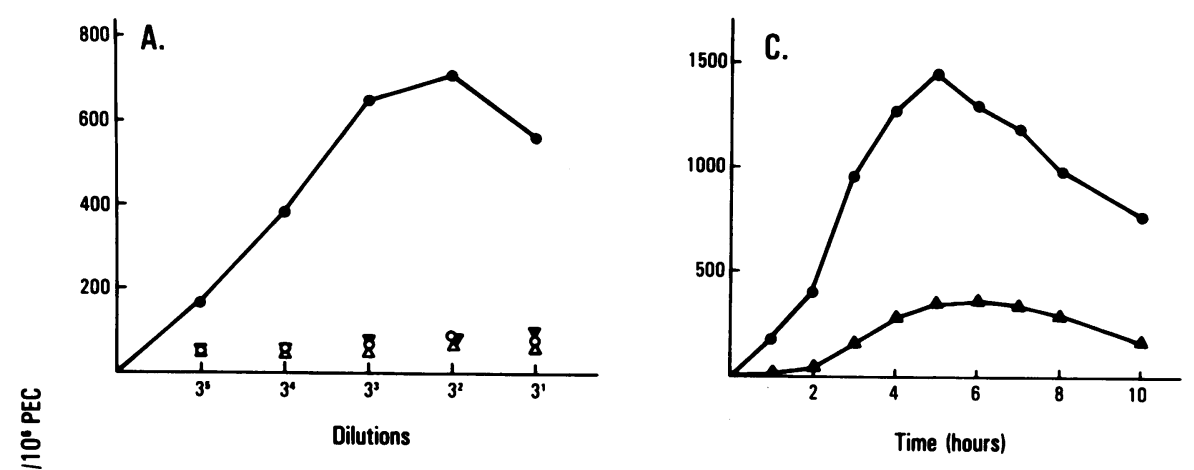

Figure 1. Induction and enhancement of murine PCA response. $(A)$ PCA induction in murine PEC by murine MLC SN or MAbs. PEC were incubated with serial threefold dilutions of MLC SN (•), or purified Anti-CD1 1b M1/70 ( $\nabla$ ), anti-CD18 M18/2 (o), or anti$\mathrm{H} 2-\mathrm{K} \mathrm{Y} 3(\Delta)$ and assayed $5 \mathrm{~h}$ later for PCA. Neat reference concentration for each MAb was $300 \mu \mathrm{g} / \mathrm{ml}$. (B) Enhancement of cytokine MPIF induced PCA response in murine PEC by anti-

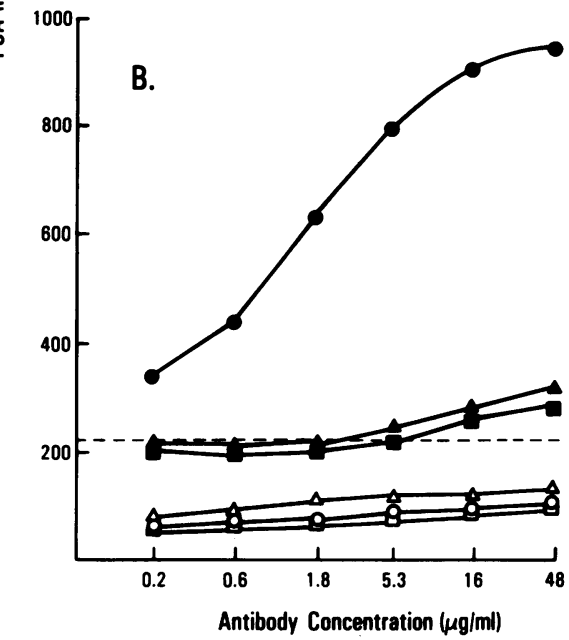

D.

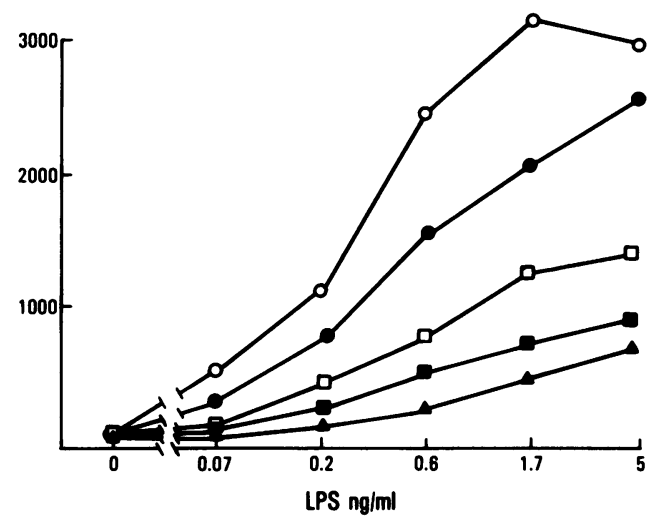

CD1 1b/CD18 antibodies. PEC were incubated with serial concentrations of anti-CD11b M1/70 (O and $\bullet$ ), anti-K Y3 ( $\triangle$ and $\Delta$ ), or anti-IA 26-8-16s ( $\square$ and $\square$ ), in the absence (open symbols) or presence (closed symbols) of $2 \%$ (vol/vol) murine MLC SN for 5 h. Activity induced with $2 \%$ MLC SN alone (---). Results are representative of four independent experiments. $(C)$ Time course of PCA responses in the presence or absence of anti-CD11b specific MAb. PEC were incubated with $2 \%$ (vol/vol) MLC SN in the presence (O) or absence $(\Delta)$ of M1/70. Induced
PEC in response to ligation of PCA were assayed at intervals of incubation. (D) Enhancement of the PCA response of LPS stimulated murine PEC in response to ligation of
CD11b/CD18 by specific MAbs as surrogate ligands. PEC were incubated for $5 \mathrm{~h}$ with serial concentrations of LPS in the absence ( $\Delta$ ) of

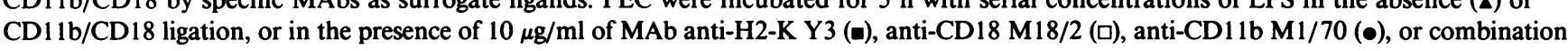
of $M 18 / 2$ and $M 1 / 70(0)$. Results are representative of three independent experiments.

$\mathrm{CD} 1 \mathrm{~b} / \mathrm{CD} 18$ or control molecule induced a de novo PCA response in PEC. In contrast, MLC SN, collected $2 \mathrm{~d}$ after the eighth round of allogeneic restimulation as a source of cytokines including MPIF, initiated a vigorous response as previously reported (10). The MLC SN usually induced 50\% maximal PCA response at a final concentration of $1-3 \%$ (vol/ vol). Synergistic enhancement of a primary MPIF-(MLC SN) initiated response was analyzed by engagement of cell surface receptors on PEC for $5 \mathrm{~h}$ in the presence of a submaximal concentration of MLC SN with or without the addition of each of the MAb. As shown in Fig. $1 B$, addition of either anti-MHC class I and class II MAb to PEC was without effect, whether in the presence or absence of MLC SN as a cytokine source. In contrast, a marked effect on the PCA response of murine PEC was observed after ligation of CD1 1b/CD18 by antibodies specific for CD1 $1 \mathrm{~b}$, the $\alpha$ chain of this receptor. In the presence of anti-CD1 $1 \mathrm{~b}$ antibody M1/70, an four- to eightfold increase in the PCA response was observed. Enhancement of the murine PCA responses was evident within $1 \mathrm{~h}$ of ligation of $\mathrm{CD} 1 \mathrm{lb} / \mathrm{CD} 18$ by MAb (Fig. $1 \mathrm{C}$ ). MAb engagement did not alter the time course of the PCA response, i.e., maximum at 4-5 $\mathrm{h}$ then a progressive decline.

The enhancement effect of CD11b/CD18 ligation was also examined using stimulation of PEC with LPS to elicit the PCA response. As shown (Fig. $1 D$ ), inclusion of anti-CD11b MAb
M1/70 or anti-CD18 MAb M18/2 induces Mo to express twoto sixfold higher PCA in LPS-initiated responses, comparable to that observed for MPIF induction. In addition, there was an even greater enhancement when both anti-CD11b MAb and anti-CD18 MAb were used together.

Characteristics of enhancement. To determine whether the degree of binding of the MAbs to the Mo surface alone was responsible for the observed effect, FACS quantitation was employed. As shown in Fig. 2, in spite of some strain variation, anti-H2-K ${ }^{\mathrm{b}} \mathrm{MAb}$ Y3 binds more effectively than M1/70 to PEC from both $\mathrm{C} 3 \mathrm{H}(A)$ and $\mathrm{C} 57 \mathrm{BL} / 6(B)$ mice. Hence, the amount of Mo surface bound IgG alone does not contribute directly to the difference between $C D 11 \mathrm{~b} / \mathrm{CD} 18$ and other surface molecules such as $\mathrm{H} 2-\mathrm{K}$ in the enhancement of the PCA response. However, it was observed that anti-CD11b/CD18 MAbs did induce aggregation of PEC within $10 \mathrm{~min}$. To determine whether cellular aggregation per se increased the catalytic efficiency of the PCA assay, rather than a quantitative increase of the molecule responsible for PCA activity, PEC were induced with MLC SN for $4 \mathrm{~h}$ followed by incubation with either anti-CD $1 \mathrm{lb} / \mathrm{CD} 18$ or anti-H2-K MAbs to aggregate the cells. It was observed (data not shown) that aggregation of cells by antiH-2K MAb after PCA induction has no effect on PCA quantitation; and even addition of anti-CD1 lb/CD18 at the end of induction of the PCA response was ineffective. Conversely, en- 


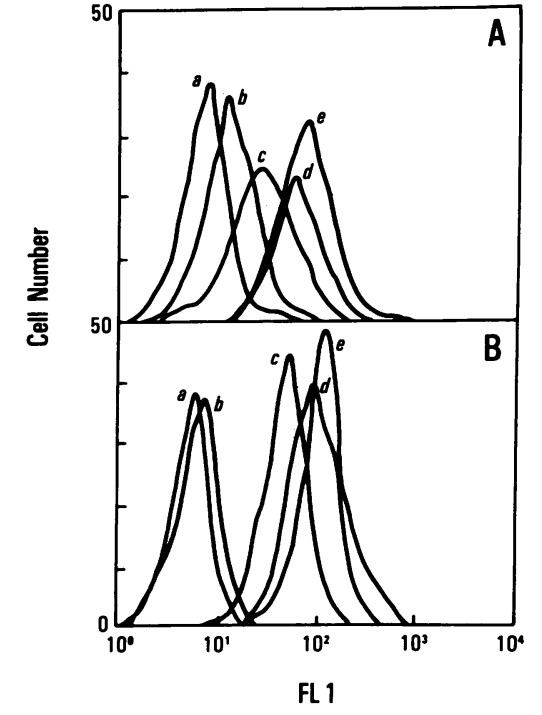

Figure 2. FACS analysis of binding of various MAbs to PEC derived from $\mathrm{C} 3 \mathrm{H}(A)$ or from C57BL/6 (B) mice. MAbs were $(a)$ no antibody control, $(b)$ anti-K $5 \mathrm{~F} 1.2,(c)$ antiCD18 M18/2, (d) antiCD1 lb M1/70, and (e) anti-K ${ }^{\mathrm{b}} \mathrm{Y} 3$.

hancement was found to require the engagement of CD1 1b/CD1 8 before, or simultaneous to, initiation of the PCA response. Brief incubation of PEC with MAb M1/70 (from 2 to $10 \mathrm{~min}$ ) before the addition of MLC SN was observed to have enhancement effect almost as great as having both $\mathrm{M1/70}$ and MLC SN together during the 5-h incubation.

The effect of ligation of CD1 1b/CD18 on the dose response to initial signaling of PEC by MLC SN was analyzed to determine if there was a differential degree of enhancement between maximal and submaximal stimulation. As shown in Table I, although enhancement by CD1 1b/CD18 MAb was observed at all MLC SN concentrations capable of eliciting an independent response, enhancement reached a maximum 3-4 times greater than the maximum elicited by excess MLC SN alone, whereas a six- to sevenfold enhancement was observed when the MLC SN was submaximal. Thus, the response is enhanced independent of the magnitude of effect of the initiating agonist.

Role of calcium mobilization. The rapid enhancement of the PCA response of Mo by engaging CD11b/CD18 suggests a

Table I. Enhancement Effect of M1/70 in Various Concentrations of MPIF

\begin{tabular}{cccc}
\hline & \multicolumn{2}{c}{ PCA induced with: } & \\
\cline { 2 - 3 } $\begin{array}{c}\text { Concentration } \\
\text { of MLC SN (\%) }\end{array}$ & MLC SN & MLC SN + M1/70 & $\begin{array}{c}\text { Enhancement } \\
\text { index * }\end{array}$ \\
\hline 0.13 & 271 & 1876 & 6.9 \\
0.25 & 496 & 2339 & 4.7 \\
0.5 & 462 & 2750 & 6.0 \\
1 & 737 & 4413 & 6.0 \\
2 & 765 & 4350 & 5.7 \\
4 & 786 & 3867 & 4.9 \\
8 & 968 & 3997 & 4.1 \\
16 & 1177 & 4156 & 3.5 \\
33 & 1357 & 4395 & 3.2 \\
\end{tabular}

PEC were incubated with various concentrations of MLC SN alone or in combination with $1 \% \mathrm{M} 1 / 70$ containing ascites for $4 \mathrm{~h} .{ }^{*}$ Denotes ratio of the PCA value in the presence of $M 1 / 70$ over the PCA value in the absence of $\mathrm{M} 1 / 70$. second signal transduction. To determine if engagement of $\mathrm{CD} 1 \mathrm{lb} / \mathrm{CD} 18$ elicited a rapid $\mathrm{Ca}^{2+}$ mobilization and flux with an increase of intracellular $\mathrm{Ca}^{2+}$, as we have observed for certain agonists of Mo (39), PEC were analyzed by loading cells with the differential fluorescent $\mathrm{Ca}^{2+}$ reporter Indo-1 and quantitating single cells by computer-assisted scanning microscopy (ACAS; Meridian Instruments). Addition of anti-CD1 1 b or anti-CD18 MAbs had no demonstrable effect on the level of free to bound Indo-1 in PEC reflecting a lack of change in the cytoplasmic concentration of free $\mathrm{Ca}^{2+}$. In contrast, upon addition of positive control ionomycin, a rapid increase of $\mathrm{Ca}^{2+}$ bound Indo-1 relative to free Indo-1 was observed (data not shown). The binding of CD1 lb/CD18 by MAbs apparently did not induce a rapid rise in intracellular level of $\mathrm{Ca}^{2+}$ within the first minute, suggesting that the PCA enhancement elicited by engagement of CD1 $1 \mathrm{~b} / \mathrm{CD} 18$ is independent of either primary or secondary calcium mobilization and must act by other mechanisms of signal transduction.

Identification of the murine PCA effector molecule. Identity of the PCA effector molecule expressed by stimulated murine Mo responsible for PCA activity was analyzed functionally, first based on the molecular requirements from plasma, and second by reconstitution with purified proteins. The plasma requirements for full acceleration of coagulation by PEC stimulated with MLC SN alone or in the presence of anti-CD11b M1/70 are given in Table II. The PCA of stimulated PEC, with or without engagement of CD11b/CD18, were observed to be equally factor X dependent and factors VII, IX, XI independent. These results indicated that PCA expressed by murine Mo mediates activation of factor $X$. This could be attributed to surface expression of the murine TF molecule as well as the factor VII or VIIa protein as the TF:VIIa binary complex, the major cellular activator of factor $\mathrm{X}$.

To analyze whether murine PEC may express both TF and VII or VIIa as the TF:VII or TF:VIIa complex, stimulated PEC were incubated with serum-free medium containing $10 \mathrm{mM}$ EDTA at $37^{\circ} \mathrm{C}$ for $30 \mathrm{~min}$ to dissociate bound VII or VIIa from TF. The cells were washed and the PCA in the presence of normal plasma or factor VII-deficient plasma was measured. As shown in Table III, after chelation of $\mathrm{Ca}^{2+}$ to disrupt the TF:VIIa complex if present, the PCA of stimulated PEC was reduced by $88 \%$, and the capacity to initiate the protease cascade in the absence of factor VII (factor VII-deficient plasma)

Table II. Functional Characteristics of the Procoagulant Effector Molecule Produced by Stimulated PEC

\begin{tabular}{lrrrrr}
\hline & \multicolumn{6}{c}{ Clotting time (s) of plasma deficient in factor } \\
\cline { 2 - 6 } & NP* & VII & IX & X & XI \\
\hline Buffer & 153 & 121 & $>180$ & $>180$ & $>180$ \\
$\quad$ Thromboplastin (mU/ml) & & & & & \\
$3 \times 10^{3}$ & 41 & 83 & 67 & 165 & 43 \\
$\quad 5 \times 10^{3}$ & 37 & 78 & 51 & 155 & 37 \\
PEC stimulated with: & & & & & \\
$\quad$ Media & 72 & 68 & 150 & $>180$ & 72 \\
MLC SN (2\%) & 41 & 45 & 70 & 150 & 52 \\
$\quad$ MLC SN $(2 \%)$ & & & & & \\
$\quad+$ M1/70 $(10 \mu \mathrm{g} / \mathrm{ml})$ & 32 & 34 & 59 & 101 & 47 \\
\hline
\end{tabular}

* Normal plasma. 
Table III. Effect of EDTA Treatment and Reconstitution with Factor VII on the PCA of Stimulated PEC

\begin{tabular}{|c|c|c|c|c|}
\hline & \multicolumn{3}{|c|}{ Clotting time of: } & \multirow{3}{*}{$\begin{array}{c}\text { PCA } \\
\text { inhibited } \\
\text { by EDTA } \\
\text { (\%) }\end{array}$} \\
\hline & \multirow{2}{*}{$\begin{array}{l}\text { Unstimulated } \\
\text { PEC }\end{array}$} & \multicolumn{2}{|c|}{ Stimulated PEC } & \\
\hline & & Untreated & EDTA-treated* & \\
\hline Normal plasma & 72 & 38 & 54 & 88 \\
\hline F.VII-deficient plasma & 68 & 39 & 71 & 96 \\
\hline F.VII-deficient plasma & & & & \\
\hline$+8 \mu \mathrm{g} / \mathrm{ml} \mathrm{F.VII}$ & 68 & 38 & 38 & 0 \\
\hline
\end{tabular}

PEC used in this study were either unstimulated or stimulated with 5\% MLC SN in combination with $10 \% \mathrm{M} 1 / 70$ culture $\mathrm{SN}$ for $5 \mathrm{~h}$. * After stimulation as mentioned above, PEC were incubated for $30 \mathrm{~min}$ with $10 \mathrm{mM}$ EDTA at $37^{\circ} \mathrm{C}$.

was abolished. This evidence that the PCA effector molecule is TF was further supported by reconstitution with purified human factor VII. Due to the species differences a requirement for a supraphysiologic concentration of VII was anticipated. Addition of factor VII to $100 \mathrm{nM}, \sim 50$-fold higher than necessary for maximal activity with human $\mathrm{TF}$, completely restored the capacity of PCA positive PEC to initiate the PCA catalytic response (Table III). Finally, kinetic analysis of the limited proteolytic activation of factor $\mathrm{X}$ to $\mathrm{Xa}$, the functional correlate of TF:VIIa, was performed by kinetic chromogenic assay, to examine whether the PEC expressed TF and catalytic activity was constituted by addition of factor VII with factor X, the substrate of TF:VIIa. Results of these studies are presented in Fig. 3. After dissociation of factor VII or other divalent ion-dependent molecules from stimulated PEC factor Xa generation was unmeasurable. Addition of factor VII reconstituted PCA activity with kinetics indistinguishable from PEC not washed with EDTA. Taken together, these results support the conclusion that the PCA induced in, and expressed on, stimulated murine PEC is the TF:VII or TF:VIIa complex.

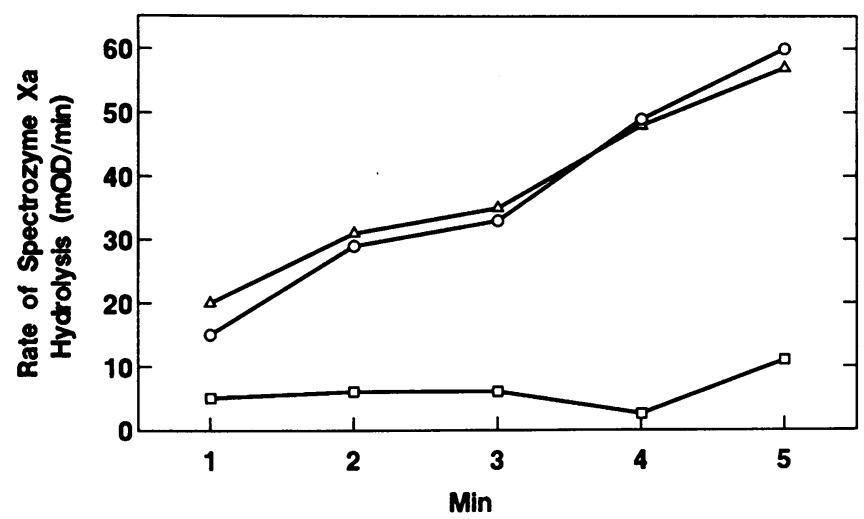

Figure 3. Kinetics of factor Xa generation by PCA positive murine PEC. Effects of dissociation of bound murine factor VII and reconstitution with purified excess human factor VII. After incubation of PEC with MLC SN for 5-h aliquots of PEC were incubated for additional $30 \mathrm{~min}$ with $10 \mathrm{mM}$ EDTA at $37^{\circ} \mathrm{C}$ or not to remove bound factor VII. PEC were washed and after resuspension in the presence of $\mathrm{Ca}^{2+}$ and factor VII or not were assayed for factor $\mathrm{Xa}$ generation. Stimulated PEC with (ם) or without (O) EDTA washing, and EDTA washed PEC in the presence of $100 \mathrm{nM}$ factor VII $(\Delta)$ was performed as described in Methods.
Human Mo. The synergistic enhancement of the Mo PCA response elicited by engaging $C D 11 \mathrm{~b} / \mathrm{CD} 18$ was also characterized in parallel studies with human cells and both MPIF and LPS initiated responses. As shown in Fig. 4, for the lymphokine elicited PCA response, both anti-CD11b MAbs OKM1 and M1/70 and anti-CD18 MAb 60.3 enhanced by two- to fivefold the response of human PBMC. Similar to the murine system, when both anti-CD11b and anti-18 MAbs were added together a higher activity was observed.

The results of studies with the LPS-initiated response are presented in Fig. $5 \mathrm{~A}$. Binding by anti-CD11b MAbs OKM1 and M1/70 enhanced significantly the PCA of human PBMC in response to various concentration of LPS. Adding both MAbs together enhanced the response somewhat more.

Enhancement by a relevant ligand. The effect of ligation of this adhesive receptor by a physiologic ligand was examined. Human PBMC were plated on surfaces coated with either purified fibrinogen, fibrin matrix, anti-CD11b/CD18 MAb, or control. As shown in Fig. $5 \mathrm{~B}$, human PBMC did not increase PCA expression as a result of attachment to these immobilized ligands or control surface alone. However, an enhanced PCA response was observed in the presence of maximal or submaximal concentrations of LPS while adherent to ligating surfaces coated with the anti-CD11b/CD18 MAb, fibrinogen, or fibrin matrix. These results suggested that binding of $\mathrm{CD} 1 \mathrm{lb} / \mathrm{CD} 18$ on the multivalent, biologically relevant substrate enhances the PCA response as observed for fluid phase affinity ligation by MAb. With Mo isolated by adherence to autologous serum, a reproducible but lower degree of enhancement (less than twofold) was observed (data not shown), suggesting that isolation by adherence may attenuate the PCA response if not elicited by a primary signal.

Cell surface expression of TF. To determine whether Mo express increased numbers of TF molecules as a result of engagement of $\mathrm{CD} 1 \mathrm{lb} / \mathrm{CD} 18$, or simply increased catalytic efficiency of the PCA, FACS analysis of human cells was used because of the existence of MAbs for human TF and methodology (24). $5 \mathrm{~h}$ after LPS stimulation, with or without engage-

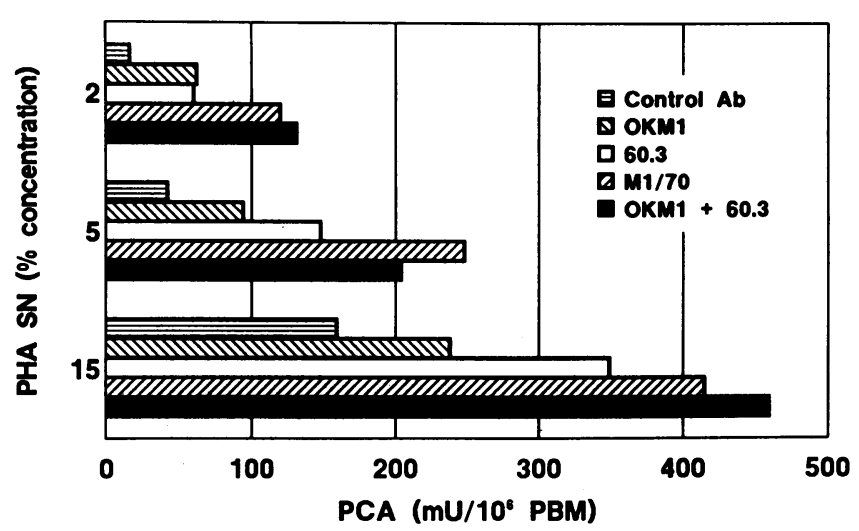

Figure 4. Enhancement of cytokine induced PCA response of human PBMC by ligation of CD1 1b/CD18. Human PBMC were incubated with various concentration of PHA SN as a source of MPIF in the presence of anti-CD11b/CD18 MAbs: CD1 lb specific M1/70 or OKM1, and CD18 specific 60.3 , or control MAb. Concentrations of OKM1, M1/70 and 60.3 used in this experiment were 8, 5, and 1 $\mu \mathrm{g} / \mathrm{ml}$, respectively. Results are representative of three independent experiments. 


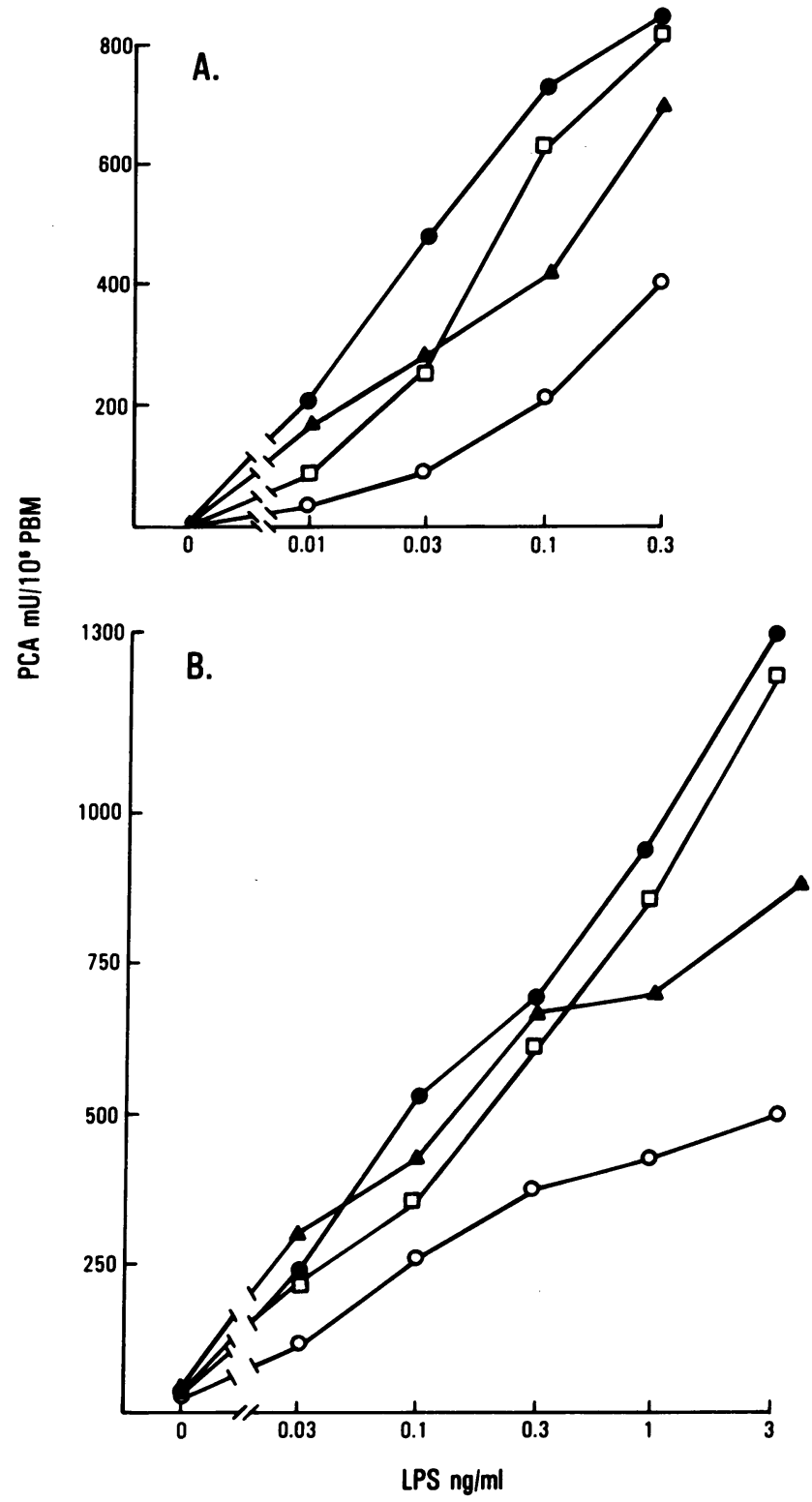

Figure 5. Enhancement of PCA response of LPS stimulated human cells. $(A)$ Enhancement of PCA response of LPS stimulated human Mo by ligation of CD11b as a surrogate ligand for the $\alpha$ chain. Human PBMC were incubated for $5 \mathrm{~h}$ with serial concentration of LPS in the absence (o) and presence of $10 \mu \mathrm{g} / \mathrm{ml}$ of MAbs: M1/70

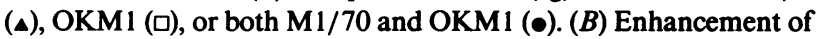
PCA response of LPS induced human Mo by the engagement of Mo surface CD1 $1 \mathrm{~b} / \mathrm{CD} 18$ by relevant ligands or specific MAb. Human PBMC were added to 96-well flat bottom plate coated with OKM1

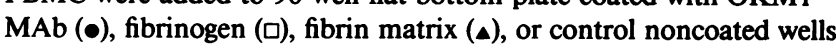
(o). Cells were stimulated with various concentration of LPS as indicated for $5 \mathrm{~h}$ and PCA was quantitated.

ment of CD11b/CD18, cell surface TF of human Mo was quantitated. As shown in Fig. 6, ligation of CD1 lb/CD18 with either immobilized M1/70 MAb or immobilized fibrinogen has no significant effect on the basal level of TF expression (left), whereas a marked increase of TF was observed for LPSstimulated cells after ligation of CD1 1b/CD18 (middle). In addition, this surface labeling with biotinylated anti-TF MAb can be completely blocked by unlabeled MAb demonstrating speci- ficity of the reaction (right). These results provide direct evidence that surface expression of TF on activated Mo is significantly enhanced after ligation of CD11b/CD18.

\section{Discussion}

The $T_{H}$ associated collaborative molecules and their complementary recognition structures on Mo that are responsible for initiating transcription, biosynthesis and cell surface expression of TF, or other PCA effector molecules have not previously been identified. These studies provide the first evidence that the integrin CD11b/CD18 (Mac-1, CR3), which is uniformly expressed on Mo, may synergize with lymphokine or LPS as primary agonists to transduce a secondary signal that results in significant enhancement of the TF response. Ligation of CD1 lb/CD18 by MAbs or by relevant ligand alone did not initiated the response nor block induction, indicating that $\mathrm{CD} 1 \mathrm{~b} / \mathrm{CD} 18$ does not serve as a receptor for $\mathrm{T}$ cell generated primary signals for transcriptional initiation of TF expression. These findings are in agreement with several recent studies showing the capacity of receptors of the CD11/CD18 class to enhance other effector functions of $\operatorname{PMNC}(28,29)$ and T cells (30). The precise level of enhancement, whether transcriptional, increased mRNA stability or protein synthesis or reduced turnover remains to be established. Nevertheless, the direct evidence of enhanced surface TF expression after ligation of CD1 1b/CD18 (Fig. 6) is in agreement with the study of Drake et al. (40) demonstrating that TF is entirely cell surface expressed on human Mo.

The complete sequence of the human tissue factor gene and putative $5^{\prime}$ regulatory elements has been described (41). Functional mapping of the regulation of transcription by the TF promoter suggests that the region encompassing the AP- 1 binding motifs could enhance constitutive transcription in COS-7 and also serum-induced putative growth factor responses (42), though definitive evidence is not yet available. Thus the hypothesis that engagement of CD11b/CD18 may signal an increase of AP-1 to enhance the TF response is a reasonable postulate and the subject of ongoing studies.

$\mathrm{CD} 11 \mathrm{~b} / \mathrm{CD} 18$ is the only surface molecule so far identified and structurally defined that mediates either initiation or enhancement of expression of the TF gene and product in Mo. $\mathrm{MAb}$ ligation of neither class II nor class I MHC, which are of similar abundance as CD1 1b/CD18, elicited an effect. Several cytokines implicated in Mo activation, including GM-CSF, TNF- $\alpha$, and IFN- $\gamma$, have not in our hands immediately enhanced TF expression (unpublished observations), though given prolonged periods of "priming" IFN $\gamma$ does enhance the TF response to LPS (43). However, TF expression may not be the only effector function of Mo that is enhanced as the result of $\mathrm{CD} 1 \mathrm{lb} / \mathrm{CD} 18$ engagement. Preliminary (unpublished) data suggest that LPS-initiated TNF- $\alpha$ production by Mo is also enhanced after ligation of CD1 lb/CD18 by MAb or by immobilized fibrinogen but not by immobilized fibronectin, further supporting the hypothesis that adhesion or other engagement of this receptor may be important in amplifying the inflammatory impact of cells of Mo lineage in cellular immune lesions.

The biological importance of enhancement of the Mo TF response, once initiated, can be considered both in qualitative and quantitative terms. First, it may be that apparent cell:cell collaboration between $T_{H}$ and Mo is mediated in part by Mo 
No LPS
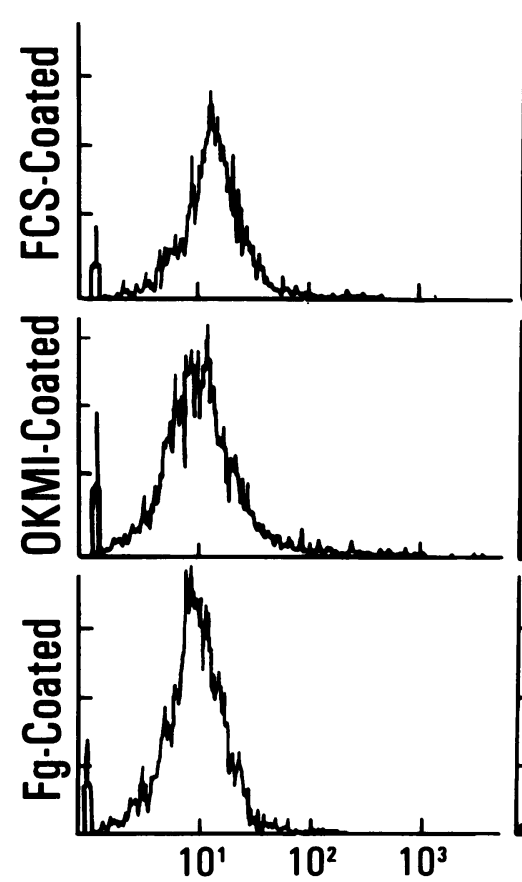
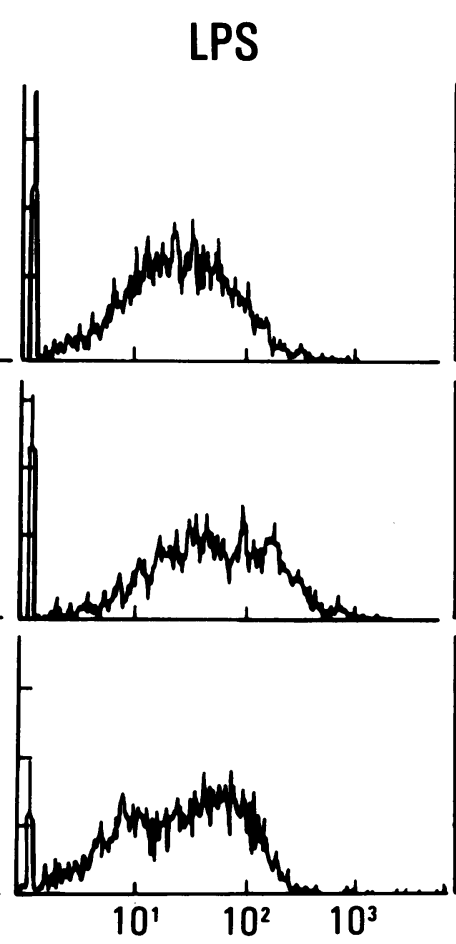

Fluorescence Intensity
LPS and Blocking MAb
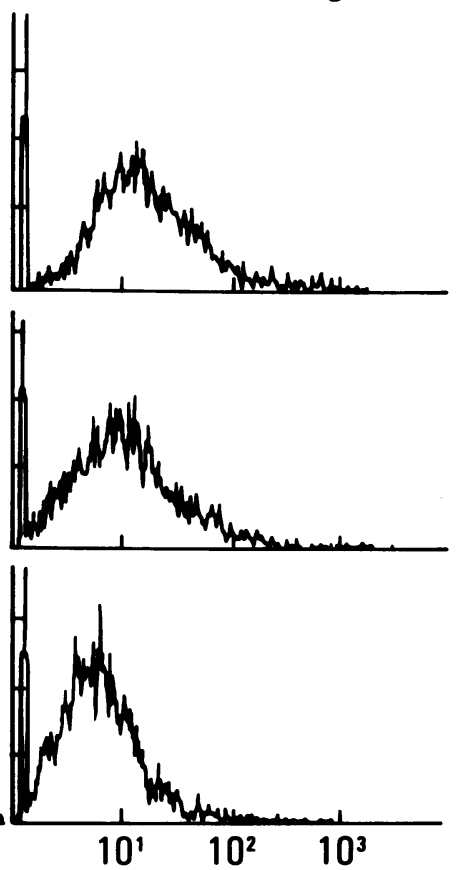

Figure 6. Quantitatively enhancement of cell surface TF of human Mo when stimulated in the presence of $\mathrm{CD} 1 \mathrm{lb} / \mathrm{CD} 18$ ligation. Human PBMC were incubated for $5 \mathrm{~h}$ without (left panels) or with (middle and right panels) $100 \mathrm{ng} / \mathrm{ml} \mathrm{LPS}$ while attaching on plate coated with control FCS (upper panels), OKM1 (middle panels), or fibrinogen (lower panels). Cells were reacted for 20 min with biotinylated anti-TF MAb 5G9, washed and the reaction revealed with streptavidinphycoerythrin, and Mo population was gated and expression of TF determined. Samples on the right panels were incubated with unlabeled 5G9 for $3 \mathrm{~min}$ before adding the biotinylated Ab.

CD1 $1 \mathrm{~b} / \mathrm{CD} 18$ engagement by the $\mathrm{T}_{\mathrm{H}}$ cell. Second, induction of TF expression by Mo and vascular endothelial cells has been implicated in a variety of cellular immune responses (4-8) as well as in the pathogenesis of disseminated intravascular coagulation and thromboembolic disease (44-47). An increase of TF expression should lead to greater impact of this pathway at sites of action. It is reasonable to hypothesize that in inflammatory settings binding of fibrin $(18,19)$, perhaps factor $X(17)$, and presumably $\mathrm{C} 3 \mathrm{bi}$ coated microorganisms $(21,23)$ by $\mathrm{CD} 11 \mathrm{~b} / \mathrm{CD} 18$ would contribute to local induration, fibrin deposition, and chemotaxis as a consequence of enhancement of TF expression by Mo. As a more delayed effect over 1-2 d, engagement of CD11b/CD18 results in Mo activation closely resembling that elicited by IFN- $\gamma$ (27). Taken together, the modulation of cell functions through $\mathrm{CD} 1 \mathrm{lb} / \mathrm{CD} 18$ engagement may have diverse consequences which we hypothesize may play important roles in Mo mediated effector responses.

\section{Acknowledgments}

We thank W. Yushak and J. Royce for technical assistance, W. Wiltse for expert assistance in the ACAS cytometry, Drs. D. Altieri, N. Mackman, and W. Ruf for helpful discussions, Dr. D. Dialynas for human MLC SN, Dr. L. Sherman for MAb Y3 and 5F1.2, and Ms. B. Parker for preparation of the manuscript.

This is manuscript No. 6148-IMM from the Department of Immunology of the Research Institute of Scripps Clinic. These studies were supported by National Institutes of Health grant P01 CA-41085 from the National Cancer Institute.

\section{References}

1. Broze, G. J., 1982. Binding of human factor VII and VIIa to monocytes. J. Clin. Invest. 70:526-535.
2. Wildgoose, P., K. L. Berkner, and W. Kisiel. 1990. Synthesis, purification, and characterization of an $\mathrm{Arg}_{152} \rightarrow$ Glu site-directed mutant of recombinant human blood clotting factor VII. Biochemistry. 29:3413-3420.

3. Gregory, S. A., J. H. Morrissey, and T. S. Edgington. 1989. Regulation of tissue factor gene expression in the monocyte procoagulant response to endotoxin. Mol. Cell. Biol. 9:2752-2755.

4. Ryan, J., and C. L. Geczy. 1987. Coagulation and the expression of cell-mediated immunity. Immunol. Cell. Biol. 65:127-139.

5. Levy, G. A., J. L. Leibowitz, and T. S. Edgington. 1981. Induction of monocyte procoagulant activity by murine hepatitis virus type 3 parallels disease susceptibility in mice. J. Exp. Med. 154:1150-1163.

6. Dindzans, V. J., P. J. MacPhee, L. S. Fung J. L. Leibowitz, and G. A. Levy. 1985. The immune response to mouse hepatitis virus: expression of monocyte procoagulant activity and plasminogen activator during infection in vivo. J. Immunol. 135:4189-4197.

7. Geczy, C. L., and P. A. Myer. 1982. Leucocyte procoagulant activity in man: an in vitro correlate of delayed-type hypersensitivity. J. Immunol. 128:331336.

8. Geczy, C. L., E. Farram, D. Moon, P. Meyer, and I. McKenzie. 1983. Macrophage procoagulant activity as a measure of cell-mediated immunity in the mouse. J. Immunol. 130:2743-2749.

9. Gregory, S. A., and T. S. Edgington. 1985. Tissue factor induction in human monocytes. Two distinct mechanisms displayed by different allo-antigen responsive T cell clones. J. Clin. Invest. 76:2440-2445.

10. Fan, S.-T., and T. S. Edgington. 1988. Clonal analysis of mechanisms of murine T helper cell collaboration with effector cells of macrophage lineage. $J$. Immunol. 141:1819-1827.

11. Ryan, J., and C. L. Geczy. 1986. Characterization and purification of mouse macrophage procoagulant inducing factor. J. Immunol. 137:2864-2870.

12. Gregory, S. A., R. S. Kornbluth, H. Helin, H. G. Remold, and T. S. Edgington. 1986. Monocyte procoagulant inducing factor: a lymphokine involved in the T cell-instructed monocyte procoagulant response to antigen. $J$. Immunol. 137:3231-3239.

13. Fan, S.-T., A. L. Glasebrook, and T. S. Edgington. 1990. Clonal analysis of $\mathrm{CD}^{+} \mathrm{T}$ helper cell subsets that induce the monocyte procoagulant response. Cell. Immunol. 128:52-62.

14. Fan, S.-T., D. C. Altieri, and T. S. Edgington. 1988. Mac-1 enhancement of the tissue factor response of macrophages. Blood. 72:146a. (Abstr.)

15. Hynes, R. O. 1987. Integrins: a family of cell surface receptors. Cell. 48:549-554.

16. Wright, S. D., P. E. Rao, W. E. Van Voorhis, L. S. Craigmyle, K. lida, M. A. Talle, E. F. Westberg, G. Goldstein, and S. C. Silverstein. 1983. Identifica- 
tion of the $\mathrm{C} 3 \mathrm{bi}$ receptor of human monocytes and macrophages by using monoclonal antibodies. Proc. Natl. Acad. Sci. USA. 80:5699-5703.

17. Altieri, D. C., and T. S. Edgington. 1988. The saturable high affinity association of factor $\mathrm{X}$ to ADP stimulated monocytes defines a novel function of the Mac-1 receptor. J. Biol. Chem. 263:7007-7015.

18. Altieri, D. C., R. Bader, P. M. Mannucci, and T. S. Edgington. 1988 Oligospecificity of the cellular adhesion receptor Mac-1 encompasses an inducible recognition specificity for fibrinogen. J. Cell Biol. 107:1893-1900.

19. Wright, S. D., J. I. Weitz, A. J. Huang, S. M. Levin, S. C. Silverstein, and J. D. Loike. 1988. Complement receptor three (CD1 lb/CD18) of human polymorphonuclear leukocytes recognizes fibrinogen. Proc. Natl. Acad. Sci. USA. 85:7734-7738.

20. Wright, S. D., S. M. Levin, M. T. C. Jong Z. Chad, and L. G. Kabbash 1989. CR3 (CD1 1b/CD18) expresses one binding site for Arg-Gly-Asp-containing peptides and a second site for bacterial lipopolysaccharide. J. Exp. Med. 169:175-183.

21. Arnaout, M. A., R. F. Todd III, N. Dana, J. Melamed, S. F. Schlossman, and H. R. Colten. 1983. Inhibition of phagocytosis of complement C3 or immunoglobulin G-coated particles and C3bi binding by monoclonal antibodies to a monocyte-granulocyte membrane glycoprotein (Mo 1). J. Clin. Invest. 72:171179.

22. Wozencraft, A. O., G. Sayers, and J. M. Blackwell. 1985. Macrophage type three complement receptors mediate serum-independent binding of Leishmania donovani. J. Exp. Med. 164:1332-1337.

23. Mosser, D. M., and P. J. Edelson. 1985. The mouse macrophage receptor for C3bi (CR3) is a major mechanism in the phagocytosis of Leishmania promastigotes. J. Immunol. 135:2785-2789.

24. Altieri, D. C., J. H. Morrissey, and T. S. Edgington. 1988. Adhesive receptor Mac-1 coordinates the activation of factor $X$ on stimulated cells of monocytic and myeloid differentiation: an alternative initiation of the coagulation protease cascade. Proc. Natl. Acad. Sci. USA. 85:7462-7466.

25. Zimmerman, G. A., and T. M. McIntyre. 1988. Neutrophile adherence to human endothelium in vitro occurs by CDW18 (Mo 1, Mac-1/LFA-1/GP $150,95)$ glycoprotein-dependent and independent mechanisms. J. Clin. Invest. 81:531-537.

26. Anderson, D. C., and T. A. Springer. 1987. Leukocyte adhesion deficiency: an inherited defect in the Mac-1, LFA-1 and p150,95 glycoproteins. Annu. Rev. Med. 38:175-194.

27. Ding, A., S. D. Wright, and C. Nathan. 1987. Activation of mouse peritoneal macrophages by monoclonal antibodies to Mac-1 (complement receptor type 3). J. Exp. Med. 165:733-749.

28. Nathan, C., S. Srimal, C. Farber, E. Sanchez, L. Kabbash, A. Asch, J. Galis, and S. D. Wright. 1989. Cytokine-induced respiratory burst of human Neutrophils. Dependence on extracellular matrix proteins and CD11b/CD18 integrins. J. Cell Biol. 109:1341-1349.

29. Shappell, S. B. C. Toman, D. C. Anderson, A. A. Taylor, M. L. Entman, and W. Smith. 1990. Mac-1 (CD1 lb/CD18) mediates adherence-dependent hy drogen peroxide production by human and canine neutrophils. J. Immunol. 144:2702-2711.

30. Wacholtz, M. C., S. S. Patel, and P. E. Lipsky. 1989. Leukocyte functionassociated antigen 1 is an activation molecule for human T cells. J. Exp. Med. $170: 431-448$

31. Gralnick, H. R., H. M. Givelber, J. R. Shainoff, and J. S. Finlayson. 1971 Fibrinogen Bethesda. A congenital dysfibrinogenemia with delayed fibrinopeptide release. J. Clin. Invest. 50:1819-1830.
32. Davignon, D., E. Martz, T. Reynolds, K. Kuzinger, and T. A. Springer. 1981. Monoclonal antibody to a novel lymphocyte function-associated antigen (LFA-1): mechanism of blockade of $\mathrm{T}$ lymphocyte-mediated killing and effects on other T and B lymphocyte functions. J. Immunol. 127:590-595.

33. Springer, T. A., W. S. Thompson, L. J. Miller, F. C. Schmalstieg, and D. A. Anderson. 1984. Inherited deficiency of the Mac-1, p150,95 glycoprotein family and its molecular basis. J. Exp. Med. 160:1901-1918.

34. Dialynas, D. P., D. B. Wilde, P. Marrack, A. Pierres, K. A. Wall, W. Havran, G. Otten, M. R. Loken, M. Pierres, J. Kappler, and F. W. Fitch. 1983 Characterization of the murine antigenic determinant designated L3T4a, recognized by monoclonal antibody GK1.5: expression of L3T4a by functional T cell clones appears to correlate primarily with class II MHC antigen-reactivity. Im munol. Rev. 74:29-56.

35. Oi, V. T., P. P. Jones, J. W. Golding L. A. Herzenberg and L. A. Herzenberg. 1978. Properties of monoclonal antibodies to mouse Ig allotypes H-2 and Ia antigens. Curr. Top. Microbiol. Immunol. 81:115-129.

36. Hammerling G. J., E. Rush, N. Tada, S. Kimura, and U. Hammerling. Localization of allodeterminants on $\mathrm{H}-2 \mathrm{~K}^{\mathrm{b}}$ antigens determined with monoclonal antibodies and H-2 mutant mice. Proc. Natl. Acad. Sci. USA. 79:4737-4741.

37. Morrissey, J. H., D. S. Fair, and T. S. Edgington. 1988. Monoclonal antibody analysis of purified and cell-associated tissue factor. Thromb. Res. 52:247-261.

38. Tsao, B. P., D. S. Fair, L. K. Curtiss, and T. S. Edgington. 1984. Monocytes can be induced by lipopolysaccharide-triggered $\mathrm{T}$ lymphocytes to express functional factor VII/VIIa protease activity. J. Exp. Med. 159:1042-1057.

39. Altieri, D. C., W. L. Wiltse, and T. S. Edgington. 1990. Signal transduction initiated by extracellular nucleotides regulates the high affinity ligand recognition of the adhesive receptor CD11b/CD18. J. Immunol. In press.

40. Drake, T. A., W. Ruf, J. H. Morrissey, and T. S. Edgington. 1989. Functional tissue factor is entirely cell surface expressed on lipopolysaccharide-stimulated human blood monocytes and a constitutively tissue factor-producing neoplastic cell line. J. Cell Biol. 109:389-395.

41. Mackman, N., J. H. Morrissey, B. Fowler, and T. S. Edgington. 1989. Complete sequence of the human tissue factor gene, a highly regulated cellular receptor that initiates the coagulation protease cascade. Biochemistry. 28:17551762.

42. Mackman, N., B. J. Fowler, T. S. Edgington, and J. H. Morrissey: 1990. Human tissue factor gene: functional analysis of expression in COS-7 cells. Proc. Natl. Acad. Sci. USA. 87:2254-2258.

43. Kornbluth, R. S., and T. S. Edgington. 1986. Tumor necrosis factor production by human monocytes is a regulated event: induction of TNF-alpha-mediated cellular cytotoxicity by endotoxin. J. Immunol. 137:2585-2591.

44. Niemetz, J., and K. Fani. 1973. Thrombogenic activity of leukocytes. Blood. 42:47-59.

45. Miller, C. L., C. J. Graziano, R. C. Lim, and M. Chin. 1981. Generation of tissue factor by patient monocytes: correlation to thromboembolic complications. Thromb. Haemostasis. 46:286.

46. Warr, T. A., L. V. M. Rao, and S. I. Rapaport. 1990. Disseminated intravascular coagulation in rabbits induced by administration of endotoxin or tissue factor: effect of anti-tissue factor antibodies and measurement of plasma extrinsic pathway inhibitor activity. Blood. 75:1481-1489.

47. Edgington, T. S., F. Taylor, A. Chang, W. Ruf, J. H. Morrissey, and K Blick. 1989. Arrest of cellular initiation of coagulation in vivo by a locus II factor VIIa competitive anti-tissue factor monoclonal antibody prevents lethal septic shock. Thromb. Haemostasis 62:347a. (Abstr.) 